\title{
INVESTIGATION OF MICROSTRUCTURES IN NATURALLY AND EXPERIMENTALLY DEFORMED REFERENCE CLAY ROCKS USING INNOVATIVE METHODS IN SCANNING ELECTRON MICROSCOPY
}

\author{
Guillaume Desbois ${ }^{1}$, Susanne Hemes ${ }^{1}$, Ben Laurich ${ }^{1}$, \\ MaArtje Houben $^{2}$, Jop KLaver ${ }^{1}$, Nadine Höhne ${ }^{3}$, Janos L. Urai ${ }^{1}$, \\ Gioacchino Viggiani ${ }^{4}$, and Pierre Bésuelle ${ }^{4}$ \\ ${ }^{1}$ Structural Geology, Tectonics and Geomechanics, EMR, RWTH Aachen University, \\ Lochnerstr. 4-20, D-52056 Aachen, Germany \\ ${ }^{2}$ Structural Geology and Tectonics, Utrecht University, Postbus 80021, \\ 3508 TA Utrecht, The Netherlands \\ ${ }^{3}$ Institut für Bauforschung der RWTH Aachen, Schinkelstraße 3, \\ 52062 Aachen, Germany \\ ${ }^{4}$ Laboratoire 3SR, Université J. Fourier, BP53, \\ 38041 Grenoble Cedex 9, France \\ *e-mail:g.desbois@ged.rwth-aachen.de
}

\begin{abstract}
The application of ion-beam milling techniques to clays allows investigation of the porosity at nm resolution using scanning electron microscopy (SEM). Imaging of pores by SEM of surfaces prepared by broad ion beam (BIB) gives both qualitative and quantitative insights into the porosity and mineral fabrics in $2 \mathrm{D}$ representative cross-sections. The combination of cryogenic techniques with ion-beam milling preparation (BIB and FIB, focused ion beam) allows the study of pore fluids in preserved clay-rich samples. Characterization of the pore network is achieved, first, using X-ray computed tomography to provide insights into the largest pore bodies only, which are generally not connected at the resolution achieved. Secondly, access to 3D pore connectivity is achieved by FIB-SEM tomography and the results are compared with 2D porosity analysis (BIB$\mathrm{SEM})$ and correlated with bulk porosity measurements (e.g. mercury injection porosimetry, MIP). Effective pore connectivity was investigated with an analog of MIP based on Wood's metal (WM), which is solid at room temperature and allows microstructural investigation of WM-filled pores with BIB-SEM after injection. Combination of these microstructural investigations at scales of $<1 \mu \mathrm{m}$ with conventional stressstrain data, and strain localization characterized by strain-fields measurement (DIC digital image correlation) on the same sample offers a unique opportunity to answer the fundamental questions: (1) when, (2) where, and (3) how the sample was deformed in the laboratory. All the methods above were combined to study the microstructures in naturally and experimentally deformed argillites. Preliminary results are promising and leading toward better understanding of the deformation behavior displayed by argillites in the transition between rocks and soils.
\end{abstract}




\section{Introduction}

Due to their low permeability and possible self-sealing properties in natural conditions, clays are considered to be potential host rocks for nuclear-waste disposal in deep geological formations and for the development of hydrocarbon resources. In clay rocks, the morphology of the pore network is one of the fundamental parameters defining fluidtransfer properties. Unfortunately, most traditional methods fail to image directly both the porosity down to the relevant pore scale and the preserved wet microstructure. Moreover, very few studies of mechanical behavior of clay (Urai and Wong, 1994; Wang et al., 2013, 2014) include microstructural observations, though microstructures could provide useful information about the deformation mechanisms. In clays, relevant scales for microstructural investigations range from hundreds of micrometers to just a few nanometers. Because none of the microscopy methods is able to cover both representative area and volume at relevant resolutions, different methods are combined to characterize fully the porosity and mineral fabrics of the clays (Desbois et al., 2013; Hemes et al., 2015). The emergence of ion-beam milling tools (i.e. BIB and FIB) has improved microstructural investigations in fine-grained geomaterials, providing unprecedented clarity of microstructures at below the micrometer scale (Loucks et al., 2009; Curtis et al., 2010; Desbois et al., 2009, 2011b; Heath et al., 2011; Hemes et al., 2013, 2015; Houben et al., 2013, 2014a, 2014b; Keller et al., 2011, 2013a, 2013b; Klaver et al., 2012, 2015a, 2015b). Cryogenic methods combined with FIB, BIB, and SEM has delivered, for the first time, direct imaging of pores filled with original pore fluids (Desbois et al., 2008, 2009, 2013, 2014). Injection of Wood's metal (WM), as an analog of MIP, but solid at room temperature, combined with BIB has been developed to visualize effective porosity decorated with WM at a given pore-throat entry pressure (Abell et al., 1999; Hildenbrand and Urai, 2003; Lloyd et al., 2009; Klaver et al., 2015 b). The innovative methods mentioned above have thus allowed, for the first time, investigation of microstructures in natural samples and development of a new integrated approach including deformation mechanism-based microstructures. The present contribution gives a brief overview of recent technical and conceptual developments of microstructural investigations applied to reference clay rocks investigated in the context of radioactive-waste disposal in Europe (France, Belgium, and Switzerland), at the institute of Structural Geology, Tectonics and Geomechanics of the RWTH Aachen University (Germany).

\section{Toolbox to investigate relevant microstructures in mudstone}

\subsection{Combination of $X$-ray tomography and BIB/FIB-SEM analyses}

$\mathrm{X}$-ray tomography (with a voxel-edge resolution typically in the $\mu \mathrm{m}$ range) applied to clay is capable of delivering relevant information about the 3D mineral fabric on sample volumes of up to a few $\mathrm{mm}^{3}$ (Robinet et al., 2012) but offers little information about the connected porosity and visualizes only the largest pore bodies (Figure 1a,b; 

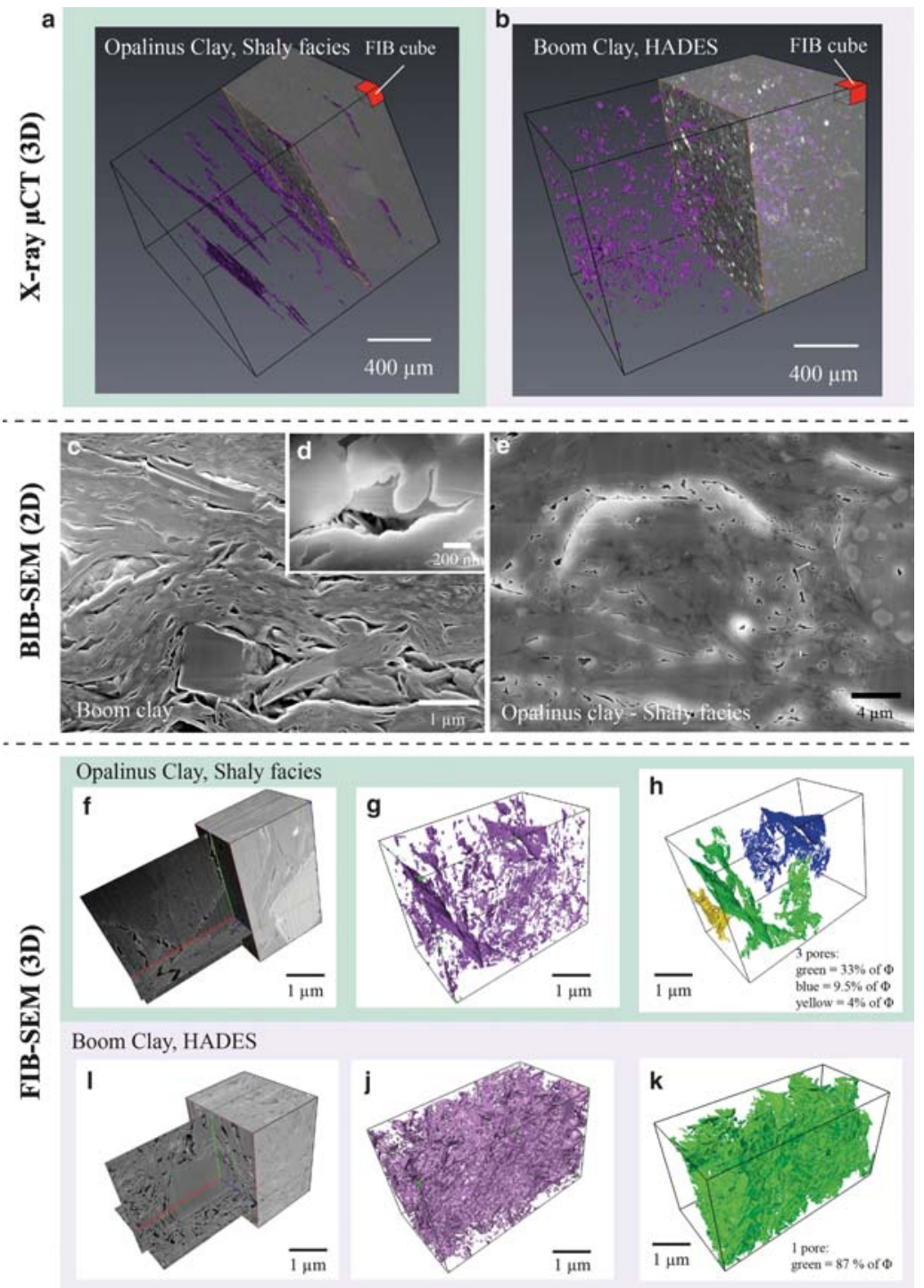

Figure 1. Multi-scale characterization of porosity in Opalinus and Boom Clays revealed by: (a-b) X-ray tomography (3D, voxel-edge resolution $=2.5 \mu \mathrm{m}$ ) of Opalinus Clay; the connected porosity with planar orientation parallel to the original bedding is interpreted to be desiccation cracks which contrasts with isolated pore bodies in the Boom Clay. (c-e) BIB-SEM (2D, pixel-edge resolution $=15 \mathrm{~nm}$ ); ( $\mathrm{f}-\mathrm{k}$ ) FIBSEM tomography (3D, pixel-edge resolution $=15 \mathrm{~nm}$ ); the porosity in the Boom Clay is highly connected and contrasts with results from the Opalinus Clay, where connected porosity represents part of the planar features observed using X-ray tomography. ( $\mathrm{f}-\mathrm{k}$ ) the total segmented porous network is shown in violet; the largest connected pore volumes with increasing volume are depicted in green, blue, and yellow; for example, in part $\mathrm{k}$ the largest connected pore volume represents $87 \%$ of the total segmented porosity. (Data courtesy of M. Houben and S. Hemes.) 
Hemes et al., 2015). Recent contributions on the characterization of porosity and mineral fabrics in reference clay rocks for research (Desbois et al., 2009; Houben et al., 2013, 2014a; Hemes et al., 2015) and organic-rich shales (Klaver et al., 2012, 2015a) demonstrate that ion-beam milling tools can be used for the preparation of heterogeneous, very fine-grained samples, suitable for SEM imaging. Ion beambased methods are opening new fields of research and allow imaging of structures which was not possible previously. The cross-sections produced by FIB and BIB are of such a high quality (the remaining topography is in the range of $5 \mathrm{~nm}$ in height; Klaver et al., 2012) that they allow direct, unambiguous investigation of the pores at the resolution $(<10 \mathrm{~nm})$ of state-of-the-art SEM. The direct detection of porosity within a truly planar 2D cross-section enables the statistical and stereological description of the porosity (Desbois et al., 2009; Hemes et al., 2013, 2015; Houben et al., 2013, 2014a, 2014b; Klaver et al., 2012, 2015a, 2015b). On one hand, BIB cross-sectioning produces large representative areas up to $2 \mathrm{~mm}^{2}$ for quantitative porosity analyses, but is restricted to $2 \mathrm{D}$ (Figure $1 \mathrm{c}-\mathrm{e}$ ). On the other hand, serial crosssectioning based on FIB-SEM resolves the 3D porosity (voxel-edge resolution of as little as $5-10 \mathrm{~nm}$; Figure $1 \mathrm{f}-\mathrm{k}$ ) but only for a limited sample volume (typically $10 \mu \mathrm{m} \times 10 \mu \mathrm{m} \times 10 \mu \mathrm{m}$ ), which results typically in a relative error of $\sim 45-50 \%$ with respect to an ideal infinite representative volume (Hemes et al., 2015; Keller et al., 2013a).

All the methods mentioned above are complementary (Desbois et al., 2013; Hemes et al., 2015) and are used in concert to provide a relevant continuity of scale, resolution, and representativeness. The BIB-SEM method bridges the 'performance gap' between the X-ray and FIB-SEM tomographies (Desbois et al., 2013). The BIB-SEM enables detailed insights into the morphologies of pores at greater resolution than X-ray tomography but on comparable cross-section areas and allows the production of large representative surfaces suitable for FIB-SEM investigations of a specific representative site within the BIB cross-section (Figure 2).

\subsection{Preservation of hydrated microstructures by FIB/BIB-cryo-SEM}

The relevance of microstructures observed in dried clay rocks often remains questionable because the shrinkage of clay minerals could damage the fine microstructure critically. Pores filled with original pore water in mudrocks can be imaged directly in preserved conditions by using cryogenic methods combined with FIB-SEM(Figure $3 a+b$ ) (Desbois et al., 2009). Slushy nitrogen $\left(-193^{\circ} \mathrm{C}\right)$ was used to first quench the pore water. Quenched samples were cross-sectioned with FIB within a cryo-SEM where the sample was maintained at a cryo-temperature $\left(-160^{\circ} \mathrm{C}\right)$ and microstructures imaged on FIB cross-sections (Desbois et al., 2009). A novel BIB-cryo-SEM instrument was developed recently for imaging microstructures in preserved clay samples and related pore fluids (Figure 3c,d; Desbois et al., 2013). In comparison with the FIBcryo-SEM method, the BIB-cryo-SEM method allows investigation of much larger representative cross-sections (in the range of $\mathrm{mm}^{2}$ ). Drying by water sublimation 


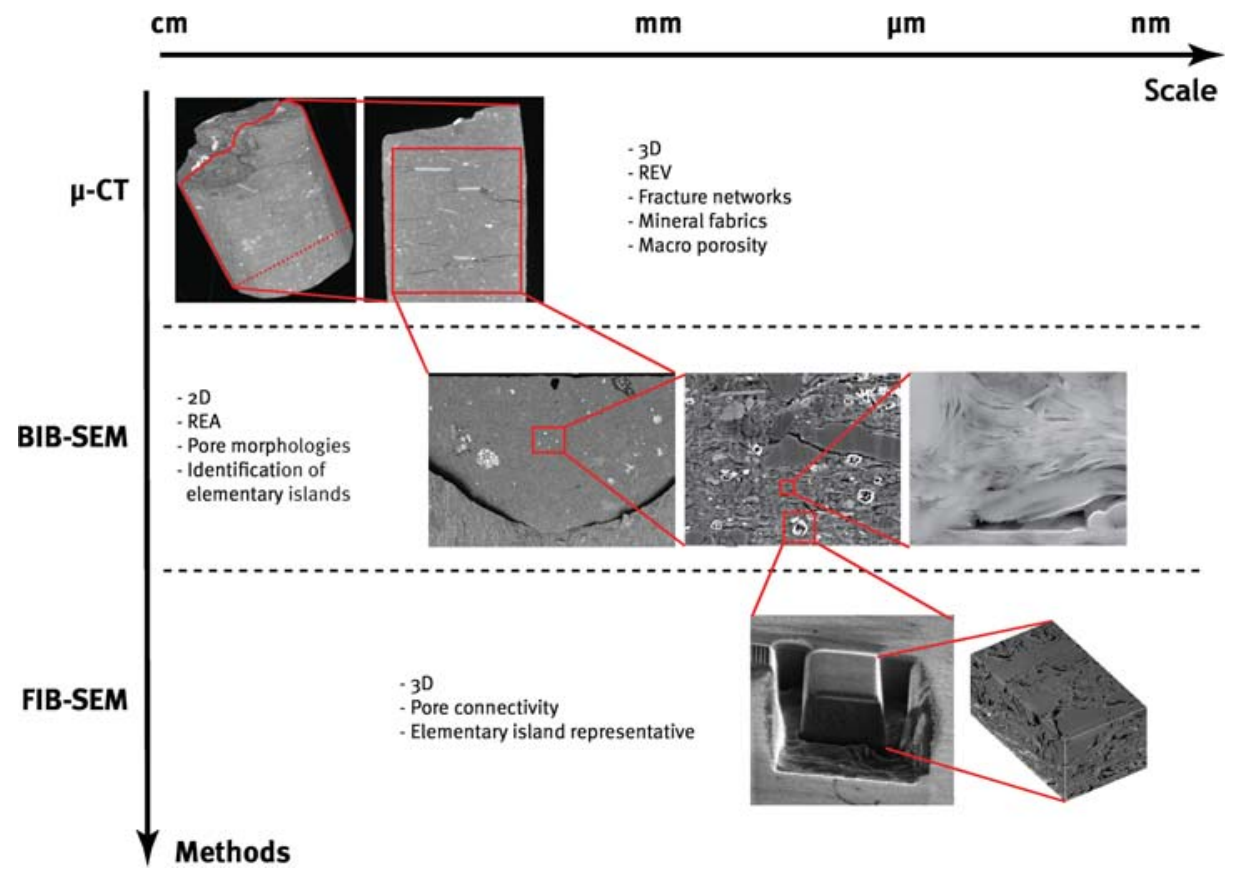

Figure 2. Multi-scale and complementary methods for microstructural investigations in fine-grained, poorly permeable, clay-rich geomaterials. None of the methods ( $\mu$ CT, BIB-SEM, and FIB-SEM) is able to describe a representative region with a resolution suitable for imaging microstructures which are $<1 \mu \mathrm{m}$ in scale and in 3D. Each method has its own niche of application and the methods are complementary.

within the SEM (Figure 3c,d) was also used to estimate pore-scale damage after drying (Desbois et al., 2013).

\subsection{Combining Wood's metal impregnation and BIB-SEM}

Wood's Metal Injection (WMI) (the alloy consists of 50\% bismuth [Bi], 25\% lead $[\mathrm{Pb}], 12.5 \%$ tin $[\mathrm{Sn}]$, and $12.5 \%$ cadmium [Cd]) is analogous to MIP (Hildenbrand and Urai, 2003; Klaver et al., 2015b) with comparable values of surface tension of the fluid $(\gamma=0.420 \mathrm{~N} / \mathrm{m})$ and wetting angle $\left(\varphi=140^{\circ}\right)$ (Abell et al., 1999; Hildenbrand and Urai, 2003). The WMI is accomplished at a temperature slightly above the melting point of $\mathrm{WM}\left(70^{\circ} \mathrm{C}\right)$, which fills the pores and then solidifies upon cooling to room temperature. The WM-filled pores may, thus, be investigated using BIBSEM (Figure 4). The amount of metal entering the sample at a given pressure $(P, \mathrm{~Pa})$ is equal to the pore volume accessible through pore throats with corresponding diameters (Washburn, 1921). This approach has the unique advantage of providing information about pore connectivity (3D) from 2D cross sections, at a given entry pressure. 

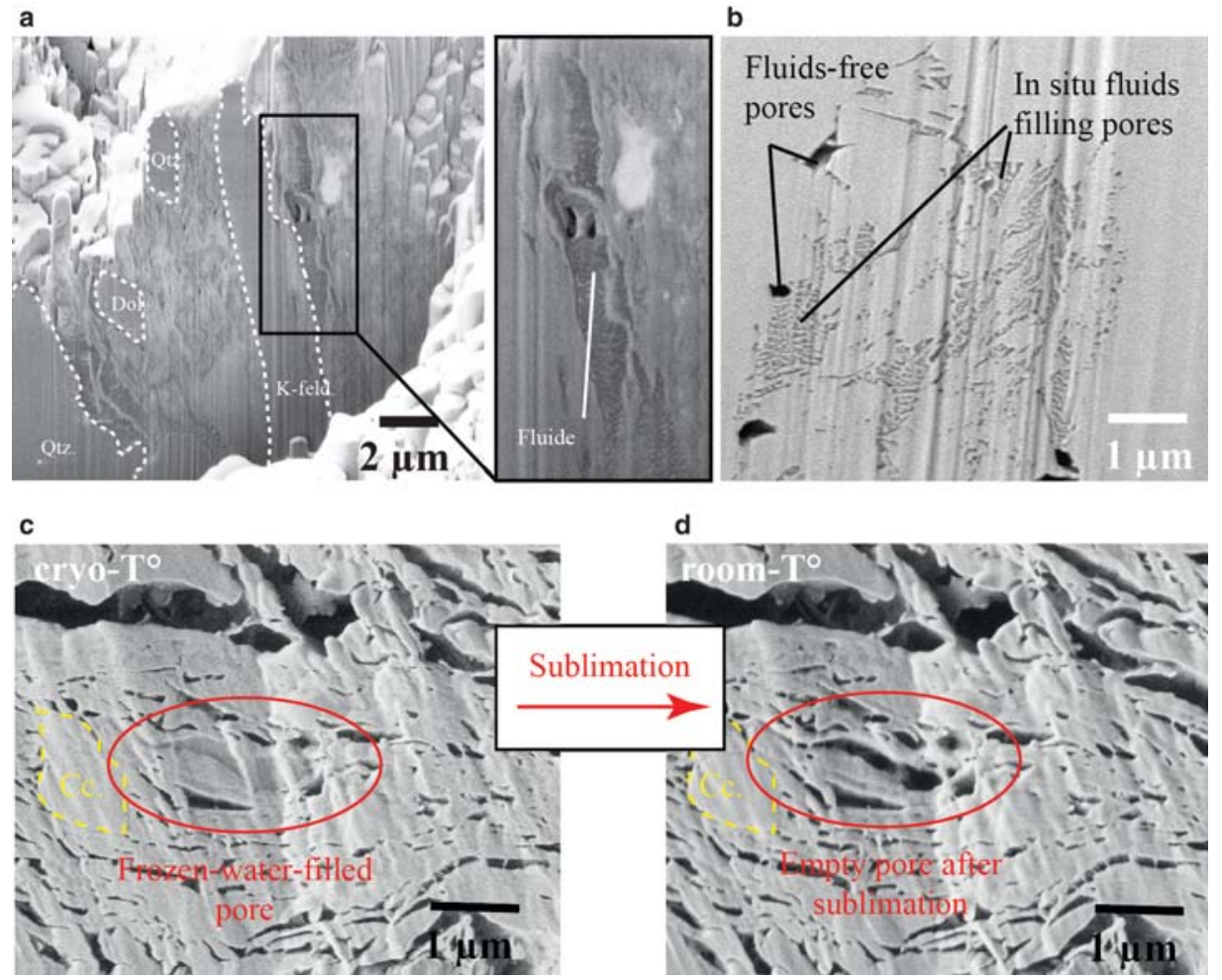

Figure 3. Direct imaging of pore fluid in wet-preserved Opalinus and Boom Clays by FIB/BIB-cryo-SEM. (a, b) A fully fluid-saturated pore in Boom Clay (a, reproduced from Desbois et al., 2009) and Opalinus Clay (b), revealed by FIB-cryo-SEM. (c) Partly desaturated pore network in the Boom Clay revealed by BIB-cryo-SEM. In this image only one pore (within the red circle) is fluid-filled. (d) Drying by sublimation $\left(-160^{\circ} \mathrm{C} \rightarrow 20^{\circ} \mathrm{C}\right.$ at a vacuum $>5 \times 10^{-5}$ mbar) removes pore fluid (Desbois et al., 2014).

\section{Applications to reference clay rocks for research}

\subsection{Microstructures in undeformed clays}

The application of ion-beam milling techniques to clays and shales allows investigation of pore space with unprecedented clarity and resolution (down to a few nanometers) within representative elementary areas under SEM. The SEM imaging of pore structures on ion beam-prepared surfaces gives both qualitative and quantitative insights into porosity within 2D cross-sections (Desbois et al., 2009; Hemes et al., 2013, 2015; Houben et al., 2013, 2014a, 2014b; Klaver et al., 2012, 2015a, 2015b). Segmentation of porosity combined with segmentation of mineralogy provides porosity-related mineralogy maps and results in the concept of "elementary building blocks" (Houben et al., 2014a; Hemes et al., 2015, after Desbois et al., 2011a). Also observed here was the fact that the 


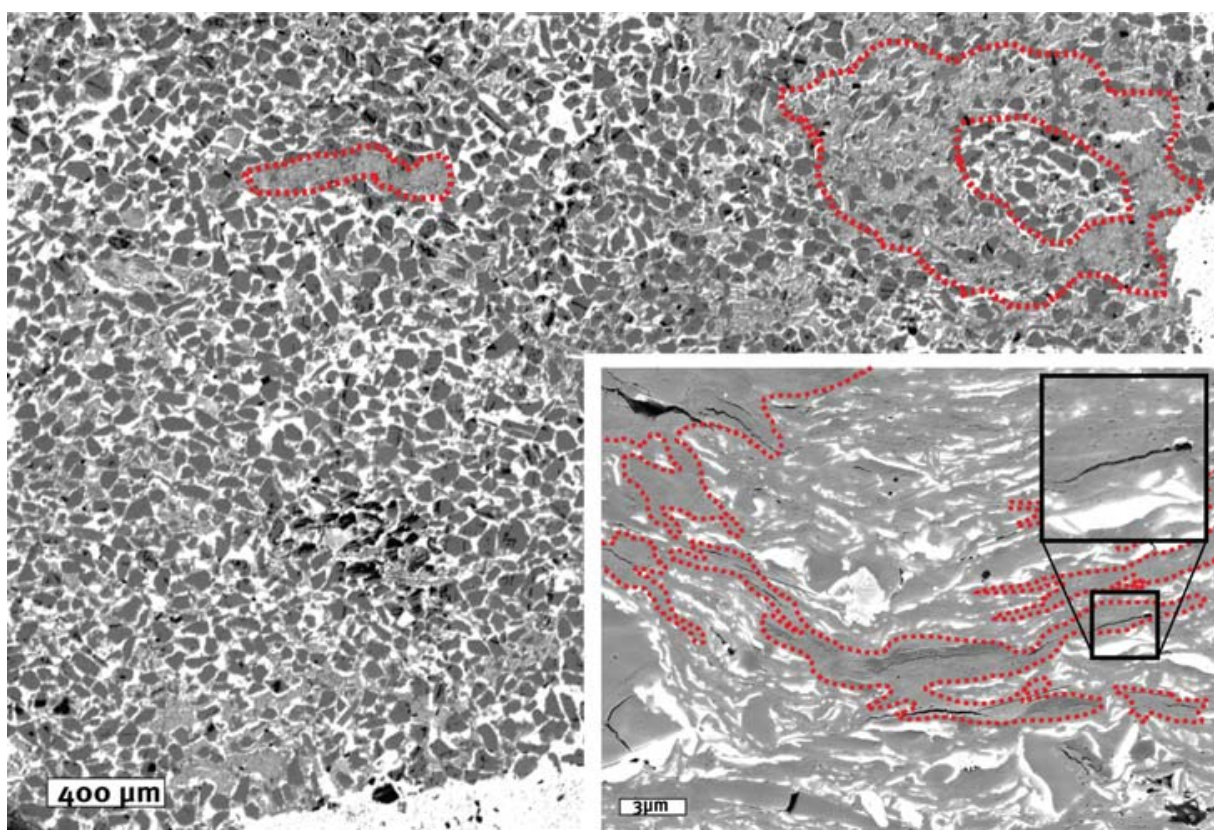

Figure 4. BIB-SEM cross-section of a Boom Clay impregnated with Wood's metal (WM) at a maximum entry injection pressure of $316 \mathrm{MPa}$, corresponding to an accessible pore-throat diameter of $\sim 4.1 \mathrm{~nm}$ (after Klaver et al., 2015). Most of the porosity is filled with WM, indicating highly connected porosity with pore throats of as little as $4.1 \mathrm{~nm}$ in diameter. At high-resolution, a region (inset) bounded by dashed red lines indicates that, locally, some of the clay matrix is not filled with WM. These regions without WM are interpreted to have been compacted during the injection of WM, thereby closing the accessible pore throats (Klaver et al., 2015).

distribution of pore-area sizes is power-law distributed suggesting the self-similarity of pores in the clay matrix (Hemes et al., 2013, 2015; Houben et al., 2013, 2014a). This was used to extrapolate the pore-size distribution, including pores not visible at the resolution of SEM. At first order, this approach allows up-scaling by estimating the porosity as measured by MIP. The combination of cryogenic techniques with ion-beam milling preparation (Desbois et al., 2008, 2009, 2012, 2013, 2014) allows study of the distribution of pore fluids in preserved clay-rich samples at a scale below a few tens of nanometers. The characterization of the pore network in a given volume is done by means of the FIB-SEM method to access to pore throats and try to establish correlation (Hemes et al., 2015) between volumetric measurements (FIB-SEM) using 2D porosity analysis (BIB-SEM) and bulk porosity measurement (e.g. MIP). Early results indicate a clear difference in pore connectivity when comparing the Opalinus and Boom Clays: the porosity in the Boom Clay is connected to a significant extent at the resolution of SEM (voxel-edge resolution of $\sim 15 \mathrm{~nm}$ ) whereas in the Opalinus Clay the porosity is mostly isolated (Figure 1a,b). 
The study of microstructures in Boom Clay using BIB-cryo-SEM (Desbois et al., 2014) suggests a more complex pore-fluid distribution than that found by Desbois et al. (2009; Figure 3a), where all visible pores were filled with pore fluid. The BIBcryo-SEM technique showed that the majority of visible pores $(>50 \mathrm{~nm}$ in diameter) do not contain fluid (Figure 3c,d), suggesting that the water content measured by weight loss can be attributed to clay aggregates, hence in pores $<50 \mathrm{~nm}$ in diameter. Because fluid-free pores are not expected in situ in clay formations, the present authors conclude that the procedure used to preserve the original clay cores is not efficient. In addition, observations of evolution of microstructures before and after drying by sublimation of water suggest four types of typical drying damage caused by the shrinkage of clay (Desbois et al., 2014). Nevertheless, quantification of pore size and pore morphologies before and after drying (Desbois et al., 2014) indicates no significant change in statistical pore characterization, suggesting that quantitative pore-morphology studies on large numbers of pores performed on dried samples are representative of the preserved core samples.

Early results from WMI combined with BIB-SEM (Klaver et al., 2015b) suggest that MIP is only valid for materials within a specific range of pore-size distribution and permeability (e.g. Boom Clay; Figure 4). In very poorly permeable samples (e.g. Opalinus Clay), the clay-rich matrix shows only a small amount of evidence for impregnation with WM, questioning the validity of the MIP measurement. The suggestion here is that neither molten WM nor mercury enters the pore space because of material compaction during injection at high entry pressure (Hildenbrand et al., 2003; Klaver et al., 2015b). The MIP measurements are often used as a reference, however. Early results indicate that MIP measurements need to be deployed with greater care (Klaver et al., 2015b).

\subsection{Investigation of deformation mechanisms in brittle and plastic clays deformed in the laboratory}

As mentioned above, the development of ion-beam milling tools enables the study of both mineral fabrics and porosity at relevant scales. The combination of approaches developed in parallel by the geomechanical (e.g. stress vs. strain analysis and stress/ strain field localization by DIC) and microstructural geology (e.g. microstructural analyses of deformation mechanisms) communities would, therefore, have the potential to relate experimental bulk mechanical properties with microstructures in a continuous, multi-scale description of deformation mechanisms involved in fine-grained clays. This would afford an opportunity to answer the fundamental questions: (1) when, (2) where, and (3) how the samples were deformed during the experiment in the laboratory.

The integrated approach above was applied for the first time (Höhne, 2012) to a consolidated Callovo-Oxfordian Clay from the Underground Research Laboratory (URL) at Bure (Meuse-Haute Marne, France). The clay was deformed in a triaxial cell at $2 \mathrm{MPa}$ confining pressure (plane strain compression) followed by planar DIC on optical images (the same sample as described by Bésuelle and Hall, 2011) to localize displacement 
fields. Typical microstructures of deformation observed within a strained zone identified by DIC (Figure $5 \mathrm{a}-\mathrm{d}$ ) show that the main deformation mechanism is grain refinement by grain-scale fracturing, resulting in a cataclastic fabric at shear displacements and an increase of porosity within the damaged fabric. With respect to relative stress level, detailed microstructure observations can be interpreted as a proxy for deformation
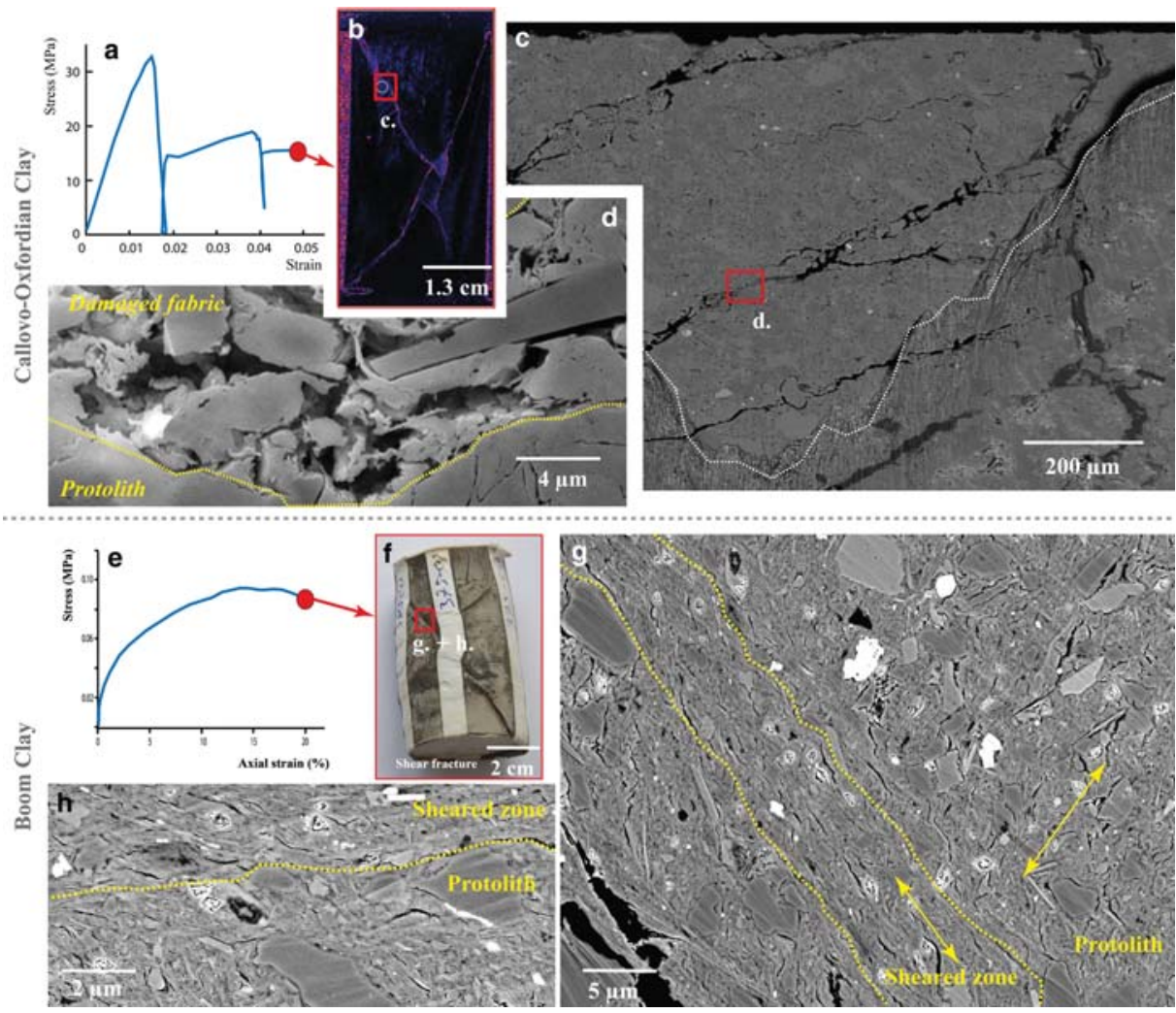

Figure 5. Early microstructural investigations of experimentally deformed Callovo-Oxfordian (upper) and Boom (lower) Clays, showing brittle and plastic clays, respectively. (a) Callovo-Oxfordian Clay was deformed at a confining pressure of $2 \mathrm{MPa}$ up to an axial strain of 5\%. (b) Planar DIC (Bésuelle and Hall, 2011) indicated a set of conjugated fractures. (c-d) BIB-SEM investigations of the regions indicated by the red boxes in parts $\mathrm{b}$ and $\mathrm{c}$ show typical cataclastic microstructures interpreted to be brittle deformation and an increase in porosity in the damaged zones. (e) The Boom Clay was deformed at a confining pressure of $0.375 \mathrm{MPa}$ up to axial strain of $20 \%$. (f) Macroscopic observation of the deformed core shows the main shear fracture. $(\mathrm{g}-\mathrm{h})$ BIB-SEM investigations within the shear zone indicated by the red box in part $\mathrm{f}$ show typical evidence for plastic deformation: the boundaries between the shear zone and the protolith are sharp; clay aggregates and clastic grains are strongly reoriented parallel to the shear direction; the porosity is reduced significantly in the shear zone; clastic grain-size reduction is observed clearly in the shear zone but the mechanisms responsible are still not known. In part c, the dashed white line indicates the boundary of the BIB cross-section. The boundaries of the shear zone are indicated by dashed yellow lines in parts e and $\mathrm{g}-\mathrm{h}$. 
(i.e. fracturing of clay matrix only $\rightarrow$ fracturing of clastic grains $\rightarrow$ rotation of broken clastic grains $\rightarrow$ cataclastic flow).

In addition, a Boom Clay sample (i.e. soft clay) was deformed in a triaxial cell at a confining pressure of $0.375 \mathrm{MPa}$. The BIB-SEM observations (Figure $5 \mathrm{e}-\mathrm{h}$ ) of the shear zones in such deformed samples show typical microstructures for plastic deformation: the boundary between the shear zone and the initial matrix are sharp; clay aggregates and clastic grains are strongly reoriented parallel to the shear direction; the porosity is strongly reduced; and the clastic grain size is smaller. A very interesting observation is that, although clastic grain-size reduction occurs in the shear zone, very little microstructural evidence exists for grain fracturing (cataclasis). That observation is in good agreement with the stress conditions used in the experiments, however. At the date of this contribution, therefore, the mechanism which led to the grain-size reduction in the shear zone has not yet been resolved.

Although, as a first approximation, the plasticity of both shales can be described by similar Mohr-Coulomb-type failure envelopes, preliminary results indicate that the full constitutive models describing their deformation and transport properties under natural conditions can be quite different. The need to include microstructural investigations to estimate comprehensively the evolution of rock performance with deformation must, therefore, be emphasized.

\subsection{Microstructures in a natural fault zone of Opalinus Clay (URL, Mont Terri, Switzerland)}

Microstructures of well preserved samples from the Main Fault (a $3 \mathrm{~m}$ wide fault zone of $\sim 10 \mathrm{~m}$ offset) in the Mont Terri Underground Research Laboratory were studied by Laurich et al. (2014) (Figure 6). Slickensided shear surfaces are ubiquitous, indicating reverse slip, which forms an anastomosing network connected by branch lines. BIBSEM investigations show that shear zones are only a few micrometers thick. In the shear zone, a complex set of processes is inferred, leading to extreme localization of strain, development of strong preferred particle orientation, the formation of nanoparticles, and local precipitation of calcite veins in releasing sections. In lenses between shear zones, homogeneous gouge is formed with a well-developed oblique foliation and removal of calcite grains by pressure solution. During progressive deformation, the number and density of slickensided shear surfaces increases, generating tectonically derived scaly clay and more homogeneous gouge. In all deformed elements of the Main Fault, the porosity is much smaller than in the undeformed Opalinus Clay and possibly decreasing in terms of permeability, which is in good agreement with a decrease in hydraulic conductivities as measured by Nussbaum and Bossart (2004) in the fault zones. An interesting observation is the almost complete absence of cataclastic microstructures. Transmission electron microscopy (TEM) of FIB lamellae of this micronwide shear zone shows a strong preferred orientation of clay minerals, including nano-sized illite particles. In TEM, the shear zones envelop hard particles and confirm an almost complete loss of porosity compared to the protolith. Inter- and transgranular microcracking, pressure solution, clay neoformation, crystal plasticity, and 


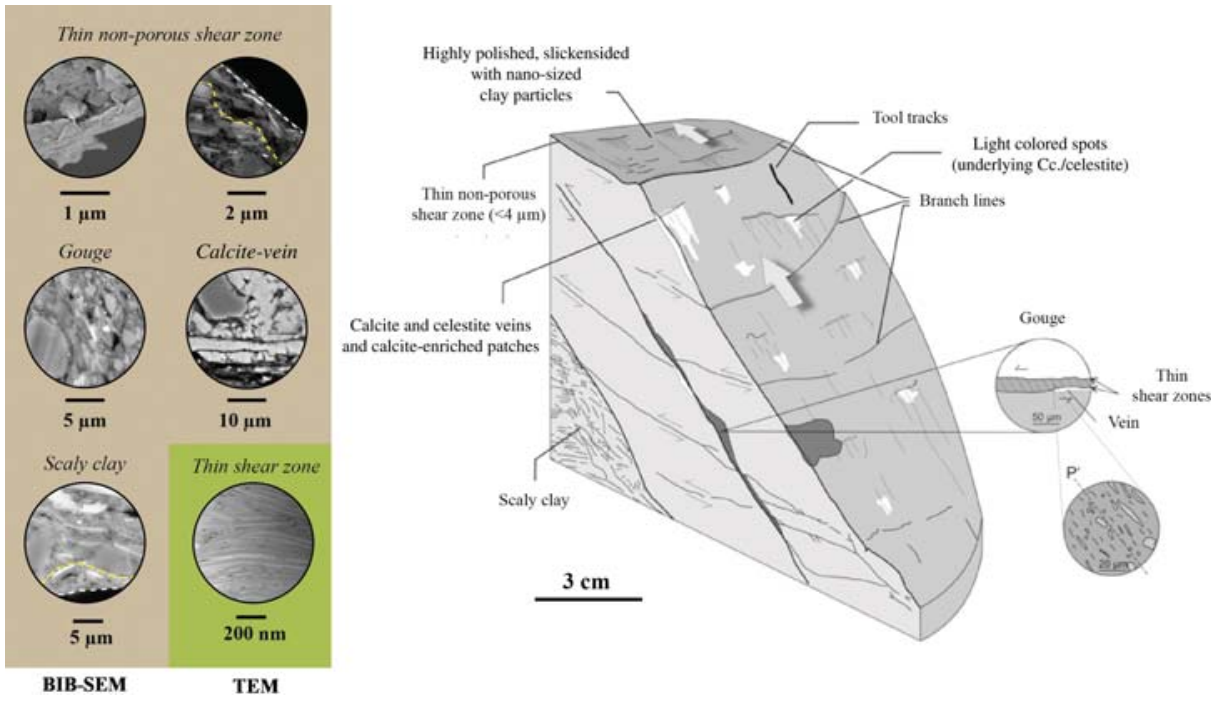

Figure 6. Typical microstructures and model of naturally deformed Opalinus Clay from the main fault in the Mont Terri URL. The inset to the left shows a selection of typical microstructures revealed by BIB-SEM (highlighted by light brown background) and TEM (highlighted by light green background): A thin, nonporous shear zone $(<2 \mu \mathrm{m})$; gouge with P-orientation of minerals; sealing of dilatant zones by calcite vein; scaly clay where only the thin outer part shows slickenside features, the inner part being comparable to undeformed Opalinus Clay; TEM of a thin, non-porous shear zone indicates strong reorientation of clay particles below the slickenside. The drawing to the right gives a generic model of faulted Opalinus Clay from the Main Fault in the Mont Terri URL. Bold arrows indicate movement of the missing block (after Laurich et al., 2014).

grain-boundary sliding are proposed to play an important role in micro-scale processes during the early stages of faulting in Opalinus Clay and thus need to be considered in extrapolating laboratory results to long-term mechanical behavior. Though Opalinus Clay is considered to be consolidated clay, the results above contrast strongly with microstructures observed in consolidated Callovo-Oxfordian Clay deformed in the laboratory where brittle deformation is observed clearly (see above). Mechanisms of deformation inferred in the laboratory may be significantly different from what actually happens in nature, where ductile deformation and self-sealing are underestimated but which result in better sealing capacities over the longer term.

\section{Conclusions}

A brief overview is given here of an innovative toolbox developed recently for the study of microstructures in clay rocks. Application of the toolbox to naturally and experimentally deformed clay rocks might offer new insights into pore and mineral fabrics and to deformation mechanisms. Further study will allow upscaling of microstructures to 
fluid-flow properties and a detailed understanding of the transitional behaviors between brittle and plastic clays.

\section{Acknowledgments}

\section{Guest editor: Thorsten Schäfer}

The authors and editors are grateful to anonymous reviewers who offered very helpful input and suggestions. A list of all reviewers is given at the end of the Preface for this volume.

\section{References}

Abell, A.B., Willis, K.L., and Lange, D.A. (1999) Mercury intrusion porosimetry and image analysis of cement-based materials. Journal of Colloid and Interface Science, 211, 39-44.

Bésuelle, P. and Hall, S.A. (2011) Characterization of the strain localization in a porous rock in plane strain condition using a new true-triaxial apparatus. Advances in bifurcation and degradation in geomaterials. Springer Series in Geomechanics and Geoengineering, 11, 345-352.

Curtis, M.E., Ambrose, R.J., Sondergeld, C.H., and Rai, C.S. (2010) Structural characterization of gas shales on the micro- and nano-scales: Canadian Unconventional Resources and International Petroleum Conference. Society of Petroleum Engineers, Calgary, Alberta, Canada, p. 15.

Desbois, G., Urai, J., Burkhardt, C., Drury, M., Hayles, M., and Humbel, B. (2008) Cryogenic vitrification and 3D serial sectioning using high resolution cryo-FIB SEM technology for brine-filled grain boundaries in Halite: first results. Geofluids, 8, 60-72.

Desbois, G., Urai, J.L., and Kukla, P.A. (2009) Morphology of the pore space in claystones - evidence from $\mathrm{BIB} / \mathrm{FIB}$ ion beam sectioning and cryo-SEM observations. eEarth, 4, 15-22.

Desbois, G., Urai, J.L., Houben, M., Hemes, S., and Klaver, J. (2011a) BIB-SEM of representative area clay structures: insights and challenges. NEA Clay Club Workshop Proceedings "Clay Under Nano- to Microscopic resolution”. NEA OECD, 6-8 September 2011, Karlsruhe, Germany.

Desbois, G., Urai, J.L., Kukla, P.A., Konstanty, J., and Baerle, C. (2011b) High-resolution 3D fabric and porosity model in a tight gas sandstone reservoir: A new approach to investigate microstructures from mm- to nm-scale combining argon beam cross-sectioning and SEM imaging. Journal of Structural Geology, 32, 580-594.

Desbois, G., Urai, J.L., Kukla, P.A., Wollenberg, U., Pérez-Willard, F., Radí, Z., and Sandor, R. (2012) Distribution of brine in grain boundaries during static recrystallization in wet, synthetic halite: insight from Broad Ion Beam sectioning and SEM observation at cryogenic temperature. Contributions to Mineralogy and Petrology, 163, 19-31.

Desbois, G., Urai, J.L., Pérez-Willard, F., Radí, Z., Offern, S., Bukkart, I., Kukla, P.A., and Wollenberg, U. (2013) Argon broad ion beam tomography in a cryogenic scanning electron microscope: a novel tool for the investigation of representative microstructures in sedimentary rocks containing pore fluid. Journal of Microscopy, 249, 215-235.

Desbois, G., Urai, J.L., Hemes, S., Brassinnes, S., De Craen, M., and Sillen, X. (2014) Nanometer-scale pore fluid distribution and drying damage in preserved clay cores from Belgian clay formations inferred by BIB-cryo-SEM. Engineering Geology, 170, 117-131.

Heath, J.E., Dewers, T.A., McPherson, B.J.O.L., Petrusak, R., Chidsey, T.C., Rinehart, A.J., and Mozley, P.S. (2011) Pore networks in continental and marine mudstones: Characteristics and controls on sealing behavior. Geosphere, 7, 429-454.

Hemes, S., Desbois, G., Urai, J.L., De Craen, M., and Honty, M. (2013) Variations in the morphology of porosity in the Boom Clay Formation: insights from 2D high resolution, BIB-SEM imaging and Mercury Injection Porosimetry. The Netherlands Journal of Geosciences (Geologie en Mijnbouw), 92, 275-300. 
Hemes, S., Desbois, G., Urai, J.L., Schröppel, B., and Schwarz, J.-O. (2015) Multi-scale characterization of porosity in Boom Clay (HADES-level, Mol, Belgium) using a combination of X-ray $\mu$-CT, 2D BIBSEM and FIB-SEM tomography. Microporous and Mesoporous Materials, 208, 1-20.

Hildenbrand, A. and Urai, J.L. (2003) Investigation of the morphology of pore space in mudstones. Marine and Petroleum Geology, 20, 1185-1200.

Höhne, N. (2012) Deformation mechanism occurring at the micro level in the Callovo-Oxfordian clay tested at two different mean stresses: insights from BIB-SEM investigations. MSc thesis at RWTH Aachen University, Germany, 95 pp.

Houben, M.A., Desbois, G., and Urai, J.L. (2013) Pore morphology and distribution in the shaly facies of Opalinus clay (Mont Terri, Switzerland): insights from representative 2D BIB-SEM investigations on mm- to nm- scales. Applied Clay Science, 71, 82-97.

Houben, M.A., Desbois, G., and Urai, J.L. (2014a) A comparative study of representative 2D microstructures in shaly and sandy facies of Opalinus Clay (Mont Terri, Switzerland) inferred from BIB-SEM and MIP methods. Marine and Petroleum Geology, 49, 143-161.

Houben, M.E., Desbois, G., Urai, J.L., de Winter, D.A.M., Drury, M.R., and Schwarz, J.-O. (2014b) Microstructure of the shaly facies of Opalinus Clay on the $\mathrm{mm}-\mathrm{nm}$ scale. Conference proceedings, Fourth EAGE Shale Workshop: Shales: What do they have in common? 6-9 April 2014, Porto, Portugal.

Keller, L.M., Holzer, L., Wepf, R., and Gasser, P. (2011) 3D geometry and topology of pore pathways in Opalinus clay: Implications for mass transport. Applied Clay Science, 52, 85-95.

Keller, L.M., Holzer, L., Schuetz, P., and Gasser, P.H. (2013a) Pore space relevant for gas permeability in Opalinus clay: Statistical analysis of homogeneity, percolation, and representative volume element. Journal of Geophysical Research, Solid Earth, 118, 2799-2812.

Keller, L.M., Schuetz, P., Erni, R., Rossell, M.D., Lucas, F., Gasser, P., and Holzer, L. (2013b) Characterization of multi-scale microstructural features in Opalinus Clay. Microporous and Mesoporous Materials, 170, 83-94.

Klaver, J., Desbois, G., Urai J.L., and Littke, R. (2012) BIB-SEM study of porosity of immature Posidonia shale from the Hils area, Germany. International Journal of Coal Geology, 103, 12-25.

Klaver J., Desbois, G., Littke, R., and Urai, J.L. (2015a) BIB-SEM characterization of pore space morphology and distribution in postmature to overmature samples from the Haynesville and Bossier Shales. Marine and Petroleum Geology, 59, 451-466.

Klaver, J., Hemes, S., Houben, M., Desbois, G., Radi, Z., and Urai, J.L. (2015b) The connectivity of pore space in fine-grained rocks: insights from high pressure Wood's Metal Injection, BIB-SEM imaging and Mercury Injection Porosimetry. Geofluids, doi: 10.1111/gfl.12128.

Laurich, B., Urai, J.L., Desbois, G., Vollmer, C., and Nussbaum, C. (2014) Microstructural evolution of an incipient fault zone in Opalinus Clay: Insights from an optical and electron microscopic study of ionbeam polished samples from the Main Fault in the Mt-Terri Underground Research Laboratory. Journal of Structural Geology, 67, 107-128.

Lloyd, R.R., Provis, J.L., Smeaton, K.J., and van Deventer, J.S.J. (2009) Spatial distribution of pores in fly ashbased inorganic polymer gels visualised by Wood's metal intrusion. Microporous and Mesoporous Materials, 126, 32-39.

Loucks, R.G., Reed, R.M., Ruppel, S.C., and Jarvie, D.M. (2009) Morphology, genesis, and distribution of nanometer-scale pores in siliceous mudstones of the Mississippian Barnett Shale. Journal of Sedimentary Research, 79, 848-861.

Nussbaum, C. and Bossart, P. (2004) Compilation of K-values from packer tests in the Mont Terri rock laboratory. Mont Terri Project, Technical Note TN 2005-10.

Robinet, J.-C., Sardini, P., Coelho, D., Parneix, J.-C., Prêt, D., Sammartino, S., Boller, E., and Altmann, S. (2012) Effects of mineral distribution at mesoscopic scale on solute diffusion in a clay-rich rock: Example of the Callovo-Oxfordian mudstone (Bure, France) Water Resources Research, 48, W05554.

Urai, J. and Wong, S. (1994) Deformation mechanisms in experimentally deformed shales. European Geophysical Union, Annual Meeting, Grenoble, 12, Supplement I, C98. 
Wang, L.L., Bornert, M., Chanchole, S., Yang, D.S., Héripré, E., Tanguy, A., and Caldemaison, D. (2013) Micro-scale experimental investigation of the swelling anisotropy of the Callovo-Oxfordian argillaceous rock. Clay Minerals, 48, 391-402.

Wang, L.L., Bornert, M., Héripré, E., Yang, D.S., and Chanchole, S. (2014) Irreversible deformation and damage in argillaceous rocks induced by wetting/drying. Journal of Applied Geophysics, 107, 108-118.

Washburn, E.W. (1921) Note on a method of determining the distribution of pore sizes in a porous material. Proceedings of the National Academy of Sciences, 7, 115-116. 